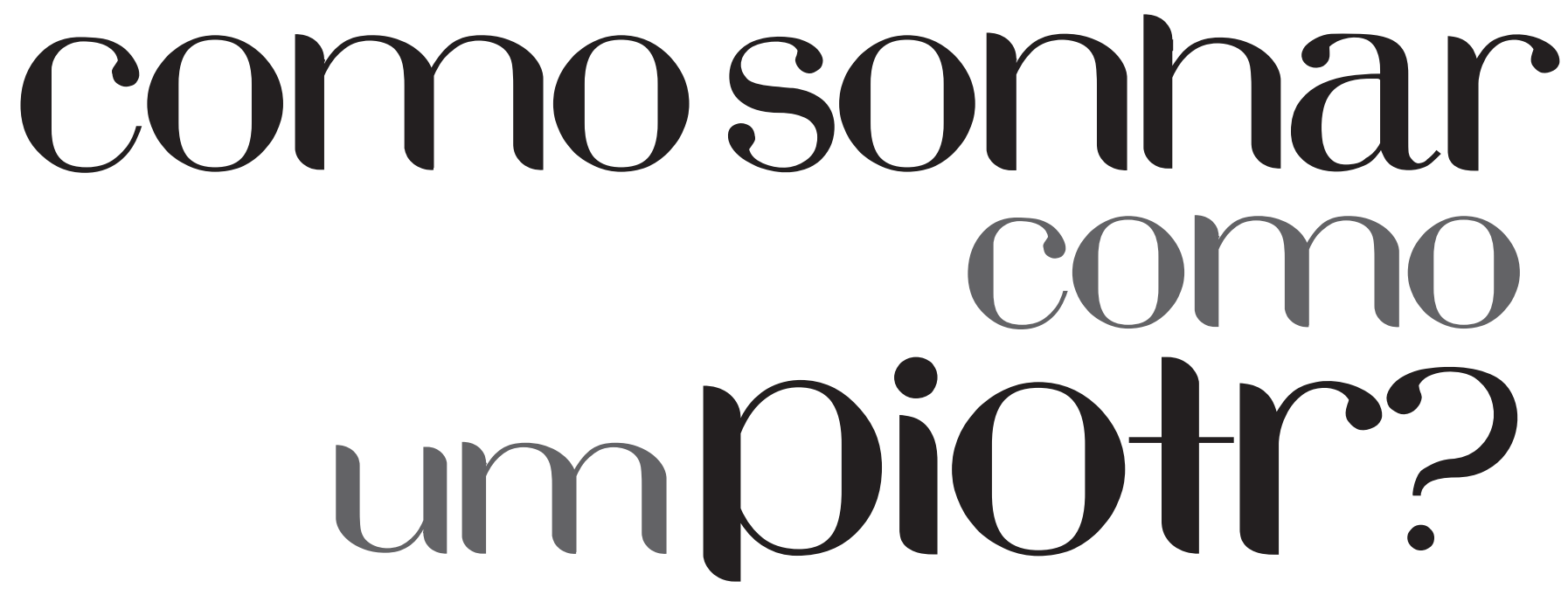

\section{Betina Leme*}

* Graduada em Psicologia (IP-USP) e Letras-Português e Linguística (FFLCHUSP), mestranda no Programa de Pós-Graduação em Literatura Brasileira na mesma universidade. E-mail para contato: betina.leme@gmail.com
PIOTR - No meu quarto cheira tanto a azeite queimado! Deve vir do lado dos velhos... Se calhar foi por isso que tive aquele sonho: imaginem, sonhei que vogava ao longo de um rio... A água era espessa como alcatrão... Foi difícil vencer a corrente, não havia margens, nem de um lado nem de outro... Passavam destroços, mas quando tentava agarrá-los desagregavam-se... Estavam carunchosos, todos podres... (Percorre o quarto de um lado para o outro, a assobiar) E se tomássemos chá? (GORKI, 1975 [1901])

O trecho citado é da peça Pequenos burgueses, de Máximo Gorki. Se você leu o texto de Thiago Fernandes, "Sonho de Piotr", publicado neste número da Opiniães, já percebeu a correspondência, aqui, com aquele momento em que é descrita uma cena que precisa ser feita: 
Eu preciso fazer uma cena, e então dizer alguma coisa.

Nessa cena o personagem relata um sonho, ele conta um sonho, um pesadelo, acho que é mais um pesadelo. Nesse sonho ele está num rio, ele diz que é um rio de água espessa, eu não gosto dessa água espessa; a palavra espessa me incomoda, é diluída demais. Água turva. Ele diz que está sendo arrastado pela correnteza, é como se fosse um,

assim, tsunami (FERNANDES, 2016).

Há mais de uma tradução dessa peça de Gorki para o português, e não é em todas que a água é "espessa". Na tradução aqui transcrita, portuguesa, a água é "espessa como alcatrão". Em uma tradução brasileira que não me foi possível alcançar a tempo para as devidas checagens, se não me faIha a memória (mas sempre pode falhar), a água também é espessa ${ }^{1}$. Na tradução brasileira mais recente até este momento, o personagem diz que "estava nadando num rio de águas grossas, parecia até piche" (Editora Hedra, 2010). Piche é um derivado do alcatrão, tanto em Portugal como no Brasil. Em alguns casos, podem ser usados como sinônimos. Entretanto, acredito que, para a maior parte dos brasileiros, nadar em águas grossas como piche deve soar sempre mais dramático do que vogar em águas espessas como alcatrão. E ai é que está: é de drama que estamos falando. É do processo criativo da montagem de uma peça teatral que estamos falando. E também é de tradução que estamos falando: como sonhar como um Piotr?

Piche (ou alcatrão) não é algo apenas espesso ou grosso ou turvo. É também visguento, xaroposo, pegajoso, denso. Mas, repare bem, não é a consistência da água que está em jogo no texto de Thiago Fernandes; é a consistência da palavra: "a palavra espessa me incomoda, é diluída demais". É de drama que se está falando, e é com palavras, dentre ou- o ainda ralo sonho de Piotr - o ainda ralo Piotr, o ainda não Piotr; aquele que, por ainda não ser, ainda não sonha. Aquele que fala, no texto de Thiago, naquele momento - aquele a quem a palavra espessa incomoda, o ainda não Piotr -, não está falando de um sonho sonhado que se traduz em palavra. Ele gira em falso diante de um sonho alheio, estranho e estrangeiro, enquanto repete palavras que lhe soam estúpidas, com vozes idiotas que não são a sua.

\section{Como sonhar como um Piotr?}

Retomemos o texto desde o início. Ele quer "falar alguma coisa", quer "encontrar a melhor maneira de falar alguma coisa". Ao texto, desde o início, vão sendo agregadas várias "coisas". Os temas, as falas, as ações vão e vêm, recorrentes, desfilam desordenados entre play e pausa, play e pausa. Embaralham-se, repetem-se com variações. Em certo momento, porém, algo se rompe: não são mais as palavras predeterminadas dos tradutores de Gorki, palavras alheias (como "espessa"); não são mais palavras diluídas. Não são mais palavras pensadas: "Eu não sei por que eu estou falando tudo isso". Podemos pressentir que já são, agora, os próprios destroços, pedaços de coisas que se desfazem quando ele tenta se agarrar a elas, merguIhado nas águas de um rio turvo e sem margens que flui. Aquele que fala é, finalmente, aquele que sonha.

Vilém Flusser, ao refletir sobre o processo de tradução, se propõe a capturar o instante exato em que se dá a passagem de uma língua para a outra:

Durante a tradução, durante esse instante ontologicamente inconcebível da suspensão do pensamento, pairo sobre o abismo do nada. "Sou" durante essa transição somente no sentido de poder ser. Sob o prisma da tradução o "cogito sum" cartesiano adquire um significado existencial imediato. Até agora os pensadores existenciais parecem não ter percebido que o nada, esse 
horizonte do ser, se manifesta "nadificante" durante o processo de toda tradução. Toda tradução é um aniquilamento. O fato existencialmente importante nesse processo é a circunstância de esse aniquilamento poder ser veberholt, ultrapassado e superado pela tradução realizada. Não se trata, porventura, de uma miniatura de morte e ressurreição? (FLUSSER, 2007).

Quando aquele que fala, no texto, se dá conta de que é, por fim, aquele que sonha, o processo de tradução está finalmente completo: Piotr sonha, logo existe. Agora ele terá novas palavras, palavras densas, para falar de seu sonho sonhado.

$\star \star \star$

Pequenos burgueses foi a primeira peça escrita por Gorki, em 1901, a pedido de ninguém menos que Stanislavski, um dos fundadores do Teatro de Arte de Moscou. Anton Tchekhov, amigo de Gorki na época, embora tenha achado a estrutura da peça um tanto quanto conservadora, reconheceu a indiscutível ousadia no conteúdo: era a primeira vez que alguém falava da mentalidade pequeno-burguesa de maneira tão desdenhosa e crítica, e no exato momento em que a sociedade já tinha certo estômago para digerir a bomba. (O que não impediu que a peça sofresse diversos cortes por parte da censura, na época.) Stanislavski, por sua vez, vê Gorki como o criador da linha sociopolítica no teatro (VÁSSINA, 2010).

O texto "Sonho de Piotr" (FERNANDES, 2016), como se pode ler em sua pequena nota de rodapé, foi derivado do processo criativo do espetáculo "Pequeno-burgueses: rapsódia em duas partes" (2014), da Cia Bruta de Arte (SP). O objetivo do grupo foi, por meio da apropriação das linhas de força da dramaturgia original, proceder a uma reescritura cênica. Numa primeira etapa, os conteúdos temáticos da dramaturgia de 1902 foram submetidos a núcleos familiares de 2014. Na segunda etapa, os atores foram instigados a desmontar a obra e explodir os limites realistas ${ }^{2}$.

\section{Referências Bibliográficas}

FERNANDES, Thiago. "Sonho de Piotr". Opiniães: revista dos alunos de literatura brasileira, FFLCH-USP, São Paulo, n. 8, 2016.

FLUSSER, Vilém. "A língua e realidade - Da tradução". In: . Língua e realidade. 3. ed. São Paulo: Annablume, 2007.

GORKI, Máximo. Pequenos burgueses. [1901] 2. ed. Tradução Gina de Freitas. Lisboa: Prelo, 1975.

GÓRKI, Maksim. Pequeno-burgueses. [1901] Tradução Lucas Simone. São Paulo: Hedra, 2010.

VÁSSINA, Elena. Introdução. In: GÓRKI, Maksim. Pequeno-burgueses. São Paulo: Hedra, 2010.

\section{Notas}

1 Mesma tradução - GORKI, Maksim. Pequenos burgueses: peça em quatro atos. Tradução de Fernando Peixoto e José Celso Martinez Correa -, três editoras: Brasiliense, 1965; Abril Cultural, 1976 (e outras posteriores, em 1979 e 1982, por essa mesma editora, que agregam a peça Mãe ao volume); Ediouro, 1986.

Se você é freguês de baixar PDF da internet, há uma versão disponível em espanhol, pela Biblioteca Digital Partido Comunista Obrero Espanhol. Entretanto, atenção: nela, a água não é espesa nem gruesa, pois não há a cena do relato do sonho: https://docs. google.com/file/d/oB3zhuSgY7HWxSU8wRFNHSjIPejQ/ edit?pref=2\&pli=1

2 Mais informações sobre o processo criativo do grupo com relação à peça Pequeno-burgueses em: http://www.ciabrutadearte.com/\#!processo/c1mım 